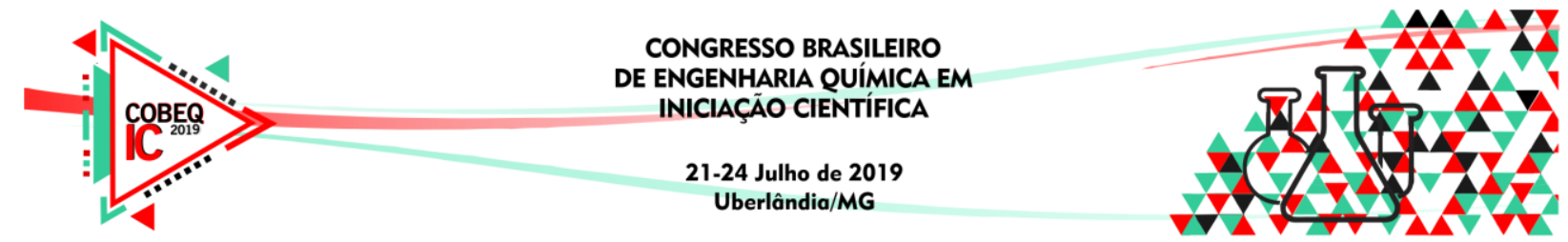

\title{
SIMULAÇÃO DO PROCESSO DE TRATAMENTO DE ÁGUA ETA UTILIZANDO O SIMULADOR DE PROCESSO PROSIMPLUS
}

\author{
T. M. BENJAMIM ${ }^{1}$, R. S. G. RIBEIRO ${ }^{1}$, E. B. MARRA ${ }^{1}$, M. R. FRAGUAS ${ }^{1}$ e C. S. S. \\ PEREIRA $^{1}$ \\ ${ }^{1}$ Universidade de Vassouras, Curso de Engenharia Química \\ E-mail para contato: thainara.benjamin@yahoo.com.br
}

\begin{abstract}
RESUMO - A responsabilidade pelos serviços de tratamento de água recai sobre os governos municipais e cada vez mais requer o envolvimento de setores acadêmicos, organizações e poder público, em pesquisa e formação de profissionais técnicos, como forma de incrementar projetos e melhoria das estações já existentes. Por isso, é oportuno o desenvolvimento de ferramentas de apoio, incluindo o aprendizado em simulação de processos. Objetivou-se com este trabalho apresentar um modelo de simulação de um sistema de tratamento de água na disciplina de modelagem e simulação do curso de Engenharia Química da Universidade de Vassouras/RJ. O presente trabalho simulou um processo de tratamento de água utilizando o software ProSimPlus, empregando operações unitárias que permitem avaliar as condições operacionais reais de uma estação compacta. Para a elaboração do fluxograma do processo da ETA no simulador utilizaram-se as informações cedidas por uma estação do município de Barra do Piraí-RJ, que atende aproximadamente 16.320 habitantes. Destaca-se que os softwares simuladores facilitam a modelagem de sistemas complexos. A avaliação dos resultados levou à conclusão de que a aplicação do software foi satisfatória, indicando ser promissora para novos experimentos, fazendo, por exemplo, simulações com diversos floculantes.
\end{abstract}

\section{INTRODUÇÃO}

A água, é um recurso indispensável para a sobrevivência de todos os seres vivos, onde na população tem um dever decisivo na qualidade de vida (Ferreira, 2005). Com isso, a legislação brasileira, por meio da Portaria de Consolidação $n^{\circ}$ 5, de 28 de setembro de 2017 do Ministério da Saúde, dispõe que a água potável para o consumo da população deve estar de acordo com o padrão de potabilidade, ou seja, com as qualidades físicas e químicas não oferecendo o risco a saúde.

O tratamento de água ocorre pela na remoção de partículas suspensas e coloidais, matéria orgânica, microrganismos e outras substâncias possivelmente deletérias à saúde humana presentes nas águas (Botero, 2009). 


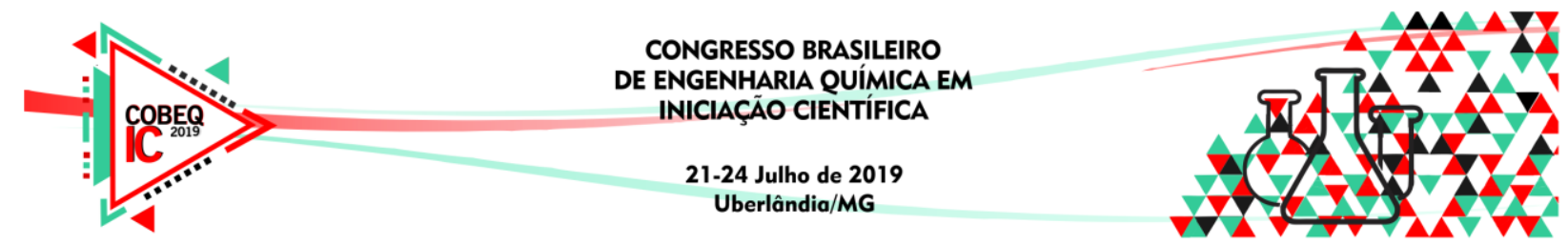

O tratamento de água convencional é dividido nas seguintes etapas: captação, adução, coagulação, floculação, decantação, filtração, desinfecção, armazenamento e distribuição para as residências, comércio e indústrias (Francisco et al., 2011).

A primeira geração de simuladores, envolvidos em projetos de novas plantas industriais, baseados nos primeiros princípios da termodinâmica realizava a simulação de apenas uma operação unitária, o que dificultava a visão geral de um projeto, por exemplo. Em seguida surgiram os simuladores mais desenvolvidos, bem como, sistemas de água de resfriamento, redes de alívio para flare, sistemas de vapor, entre outros. De acordo com Martins (2019), a utilização de simuladores em diversas áreas, propõe uma plataforma unificada para ser usada desde engenharia conceitual até a operação da planta, passando por todas as fases de projeto.

O ProSimPlus é um software de engenharia que realiza balanços de massa e energia para uma ampla gama de plantas de processamento industrial. Fornece possibilidades de simulação para processos nas áreas de petróleo e gás, química, farmacêutica, energia e outras indústrias de processo (ProSimPlus, 2017). Diante disso, o presente trabalho teve como objetivo, simular o processo de tratamento de água no software ProSimPlus, empregando operações unitárias que permitem representar os sistemas de forma mais próxima da realidade.

\section{MATERIAIS E MÉTODOS}

Para a representação do processo, desenvolveu-se no simulador um fluxograma de uma estação de tratamento de água utilizando dados reais de entrada e saída de uma ETA localizada no município de Barra do Piraí-RJ. A ETA em estudo atende aproximadamente 16.320 habitantes, com a capacidade de tratamento de $120 \mathrm{~m}^{3}$ de água. O fluxograma do processo é apresentado na Figura 1.

Figura 1 - Fluxograma do processo de ETA simulada no ProSimPlus.

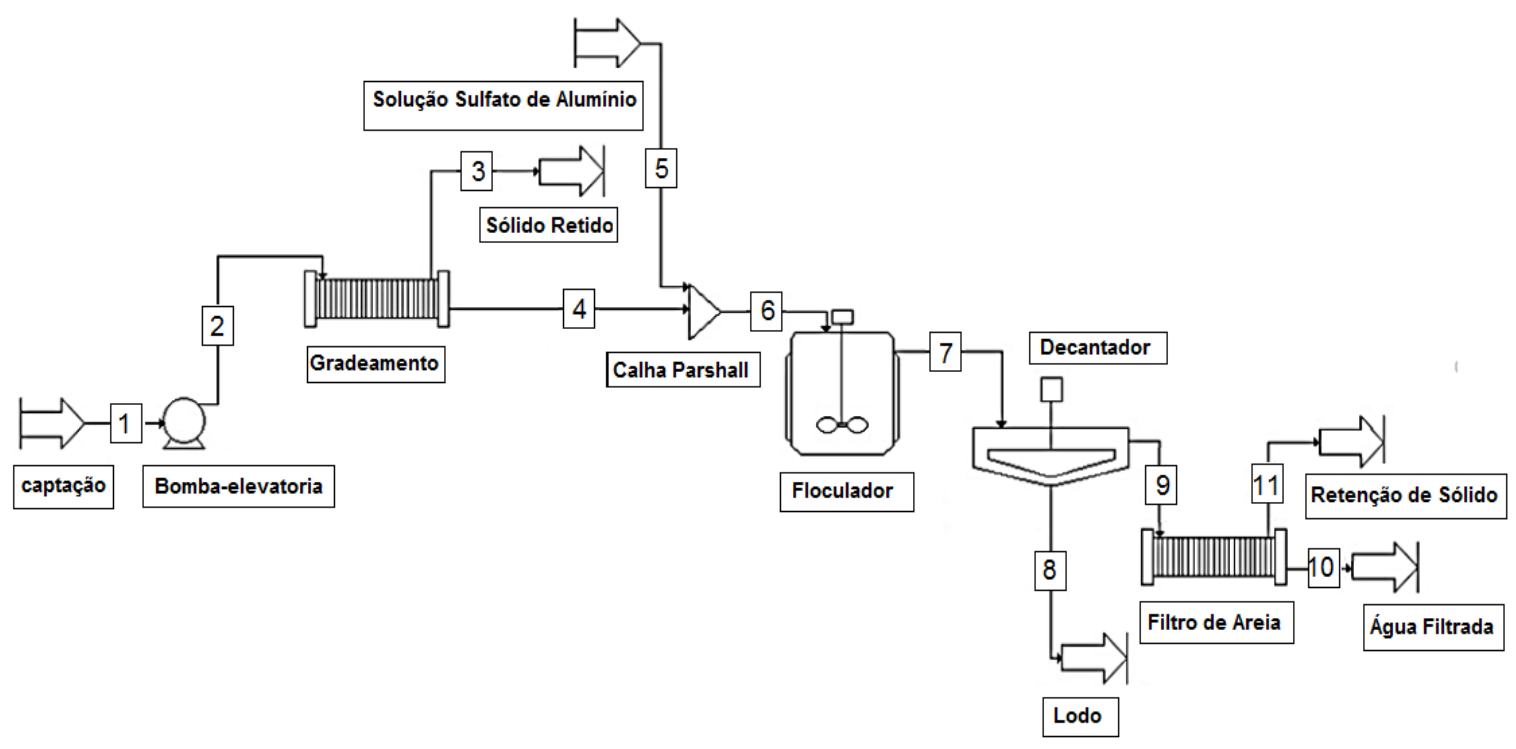




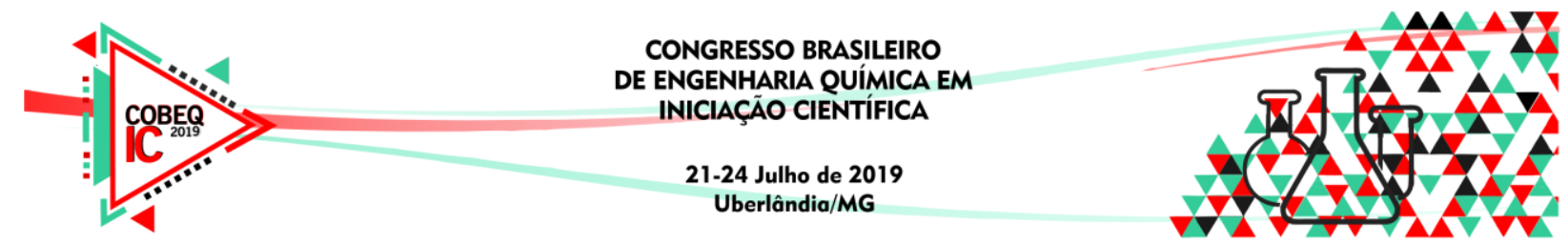

\subsection{Simulação das etapas do processo}

Na corrente de entrada, a água bruta é captada com uma vazão de $120.000 \mathrm{~L} / \mathrm{h}$ do Rio Paraíba do Sul, através de uma bomba elevatória (centrifugal Pump) identificada como a corrente 1. Posteriormente, a água passa por um gradeamento (Plate Frame Filter) representado por um filtro prensa descrito pela Corrente 2, na qual representa a remoção de elementos grosseiros que podem estar presentes na água.

No processo de mistura rápida, ocorre uma forte agitação da água com sulfato de alumínio, onde é identificado pela fórmula molecular $\mathrm{Al}_{2}\left(\mathrm{SO}_{4}\right)_{3}$. Deste modo, ocorre a desestabilização das partículas de sujeira eliminando as forças repulsivas que as mantém afastadas. $O$ equipamento utilizado para a representação de uma calha parshall foi $o$ misturador (Other Mixer), representado pela corrente 4.

O processo, descrito na corrente 5 , tem o objetivo de inserir o sulfato de alumínio utilizando uma vazão de entrada de $297 \mathrm{~L} / \mathrm{h}$. O floculante entra no sistema (corrente 6) para realizar a aglutinação de partículas. Para a representação do processo de coagulação/floculação as reações foram inseridas no banco de dados do simulador sendo empregada a operação unitária: floculador (Reaction Tank), ocorrendo a geração de hidróxido de alumínio carregado positivamente e, por essa razão, conseguindo neutralizar as impurezas coloidais carregadas negativamente que estão na água conforme descrito na Reação 1.

$$
\mathrm{Al}_{2}\left(\mathrm{SO}_{4}\right)_{3}+6 \mathrm{H}_{2} \mathrm{O} \rightarrow 2 \mathrm{Al}(\mathrm{OH})_{3}+6 \mathrm{H}++3 \mathrm{SO}_{2}^{-4}
$$

A conversão do sulfato de alumínio aconteceu com um reajuste na estequiometria com uma única reação e adição da taxa de reação no ProSimPlus, de acordo com a Tabela 1.

Tabela 1. Ajustes dos coeficientes estequiométricos no Software ProSimPlus.

\begin{tabular}{|c|c|}
\hline Componente & Coeficientes estequiométricos \\
\hline \hline Água & -6.000000 \\
\hline Sulfato de Alumínio & -1.000000 \\
\hline Hidrogênio & 3.000000 \\
\hline Hidróxido de Alumínio & 2.000000 \\
\hline Enxofre & 3.000000 \\
\hline Oxigênio & 6.000000 \\
\hline
\end{tabular}

Para representar a etapa de clarificação utilizou-se o equipamento (Clarifier). A corrente 8 representa a retenção dos flocos que se acumulam na forma de lodo. A água clarificada segue pela corrente 9 para um filtro de areia (Plate Frame Filter) com diferentes meios filtrantes como carvão (antracito) ou camadas alternadas de areia e carvão. Nesta etapa, os flocos mais leves que não decantaram, ficam armazenados nas diferentes camadas de leito filtrante. 


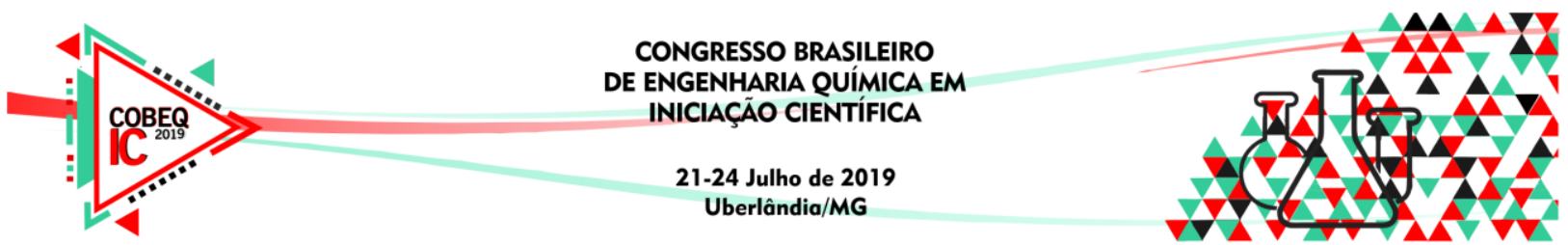

\section{RESULTADOS E DISCUSSÕES}

A Tabela 2 apresenta os resultados do balanço de massa obtido a partir da simulação do tratamento de água nas correntes de saída.

Tabela 2 - Balanços de massa das correntes 6 a 11 obtidos na simulação

\begin{tabular}{|c|c|c|c|c|c|c|}
\hline Correntes & $\mathbf{6}$ & $\mathbf{7}$ & $\mathbf{8}$ & $\mathbf{9}$ & $\mathbf{1 0}$ & $\mathbf{1 1}$ \\
\hline Etapa & $\begin{array}{c}\text { Calha } \\
\text { Parshall } \\
\text { (L/h) }\end{array}$ & $\begin{array}{c}\text { Floculador } \\
(\mathbf{L} / \mathbf{h})\end{array}$ & $\begin{array}{c}\text { Decantador } \\
\text { (sólido } \\
\text { retido) }(\mathbf{L} / \mathbf{h})\end{array}$ & $\begin{array}{c}\text { Decantador } \\
\text { (L/h) }\end{array}$ & $\begin{array}{c}\text { Filtro de } \\
\text { areia } \\
\text { (L/h) }\end{array}$ & $\begin{array}{c}\text { Filtro de } \\
\text { areia } \\
\text { (sólido } \\
\text { retido) } \\
\text { (L/h) }\end{array}$ \\
\hline Água & 120000 & 26901 & 2640 & 24260 & 7637 & 16622 \\
\hline $\begin{array}{c}\text { Sulfato de } \\
\text { alumínio }\end{array}$ & 297 & 2976 & 292 & 2684 & 845 & 1839 \\
\hline Hidrogênio & 0 & 5208 & 511 & 4697 & 1478 & 3218 \\
\hline $\begin{array}{c}\text { Hidróxido de } \\
\text { Alumínio }\end{array}$ & 0 & 134 & 13191 & 121 & 38149 & 83030 \\
\hline Enxofre & 0 & 82853 & 49303 & 33550 & 16775 & 16775 \\
\hline Oxigênio & 0 & 165 & 16233 & 149 & 46948 & 10218 \\
\hline Amônia & 0,16139 & 0,16139 & 0,01584 & 0,14554 & 0,04582 & 0,099725 \\
\hline Fluxo total & 417 & 417 & 82171 & 335 & 118 & 223 \\
\hline
\end{tabular}

No processo de decantação simulado observou-se que na corrente de saída (9) pequenas frações de hidróxido de alumínio passaram a etapa seguinte de filtração. Utilizou-se um filtro de areia para simular a etapa de remoção de odor, sabor e retenção de impurezas presentes na água e que não foram removidos na etapa anterior a filtração. Com relação à retenção de amônia nesta etapa, o processo simulado representou uma maior retenção de amônia $(0,04582$ $\mathrm{L} / \mathrm{h})$.

Cabe ressaltar que, para o sistema ocorrer com total eficiência, ou seja, sendo possível replicar totalmente a Estação de tratamento de água real, existe a necessidade da adição de um reator de desinfecção no final do processo, visto que esta operação unitária auxiliaria no sistema de tratamento com a adição de hipoclorito de cálcio para a eliminação de patógenos presentes na água de captação. Destaca-se ainda nesta simulação, a utilização de apenas alguns compostos contidos na água, sendo atribuídos somente como forma representativa.

\section{CONCLUSÃO}

O presente trabalho apresenta uma modelagem de um sistema complexo de forma rápida. A avaliação dos resultados levou à conclusão de que a aplicação do software foi satisfatória, indicando ser promissora para novos experimentos, fazendo, por exemplo, simulações com diversos floculantes. 


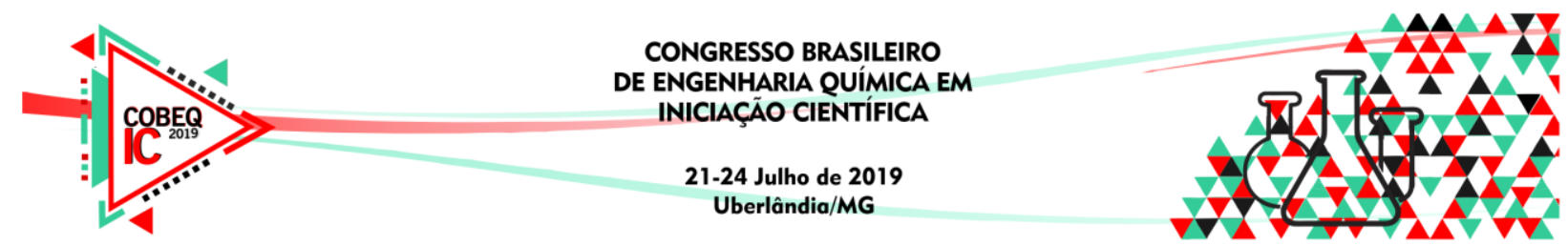

\section{REFERÊNCIAS}

BOTERO, W. G. Caracterização de lodo gerado em estações de tratamento de água: perspectivas de aplicação agrícola. Quim. Nova, Vol. 32, No. 8, 2018-2022, 2009.

DI BERNARDO, L.; DANTAS, A. D. B. . Métodos e Técnicas de Tratamento de Água. 2. ed. São Carlos: Rima Editora, 2005. v. 2. 1584 p.

FERREIRA, A.; CYNARA C. Sustentabilidade ambiental da água consumida no Município do Rio de Janeiro, Brasil. Revista Panamericana de Salud Pública 18: 93-99, 2005.

FRANCISCO, A. A.; POHLMANN, P. H. M.; FERREIRA, M. A. Tratamento convencional de águas para abastecimento humano: uma abordagem teórica dos processos envolvidos e dos indicadores de referência. Congresso Brasileiro de Gestão Ambiental IBEAS, 2011.

MARTINS F. O Simulador do Futuro Aplicado à Indústria (cap. 5) - Ebook Impactos das tecnologias na engenharia química; v. 1. Organizadora Carmen Lúcia Voigt. - Ponta Grossa (PR): Atena Editora, 2019.

PROSIMPLUS (2017). ProSimPlus Library (Standard version + rate base option). Disponível em: Acesso em: 07 nov. 2018.

WAGNER, E. G.; HUDSON Jr., H. E. Low-dosage high-rate direct filtration. Journal AWWA, vol. 74, n.5, p. 256-261, May, 1982. 